\title{
Mental Foramen Morphometry in a Population from Khyber Pakhtunkhwa (KP) Pakistan
}

\author{
Morfometría del Foramen Mental en una Población de Khyber Pakhtunkhwa (KP) Pakistán
}

\author{
Masroor Badshah",;*; Roger Soames*; Muhammad Jaffar Khan ${ }^{* * *}$; Jamshaid Hasnain ${ }^{* * * * *}$ \& Jehanzeb Khan*****
}

BADSHAH, M.; SOAMES, R.; KHAN, M. J.; HASNAIN, J. \& KHAN, J. Mental foramen (MF) morphometry in a population from Khyber Pakhtunkhwa (KP) Pakistan. Int. J. Morphol., 34(4):1228-1231, 2016.

SUMMARY: Knowledge of variations in MF location, size and shape is important when anesthetizing nerves of the mandibular region in dental procedures. The location, shape and position of the MF were determined in 119 human mandibles of unknown age and sex from different KP medical institutions. Parameters determined were: MF length and width; accessory mental foramen (AMF) width; MF and AMF to midline (MF-ML) (AMF-ML), upper (MF-UM) (AMF-UM) and lower mandibular margins (MF-LM) (AMF-LM) and posterior border of the mandibular ramus (MF-PRM) (AMF-PRM). AMF position in relation to the MF was also noted. MF were mainly oval and situated below the second premolar. MF mean length and width were: $2.4 \pm 0.89$ (right) and $2.4 \pm 0.727 \mathrm{~mm}$ (left), and $3.0 \pm$ 0.80 (right) and $2.9 \pm 0.94 \mathrm{~mm}$ (left) respectively. MF-ML, MF-UM, MF-LM and MF-PRM distances on the right and left sides were: $29.1 \pm 2.19 \mathrm{~mm}$ and $28.1 \pm 2.12 \mathrm{~mm} ; 11.0 \pm 3.99 \mathrm{~mm}$ and $11.2 \pm 3.98 \mathrm{~mm} ; 13.1 \pm 1.83 \mathrm{~mm}$ and $12.8 \pm 1.74 \mathrm{~mm}$; and $69.3 \pm 5.52 \mathrm{~mm}$ and $68.7 \pm 5.02 \mathrm{~mm}$, respectively. Double mental foramen (DMF) were observed on both sides (10.9\% right, $12.6 \%$ left) with length and width $0.7 \pm 0.42 \mathrm{~mm}$ and $0.9 \pm 0.34 \mathrm{~mm}$ (right) and $0.8 \pm 0.32 \mathrm{~mm}$ and $1.0 \pm 0.47 \mathrm{~mm}$ (left): they were mainly oval (5.8\% right, $7.56 \%$ left). DMF-MF distance was $8.9 \pm 4.58 \mathrm{~mm}$ on the right and $6.6 \pm 4.11 \mathrm{~mm}$ on the left. An oval accessory mental foramen was observed in one mandible. There was no difference between right and left MF; however differences in the parameters measured were observed in relation to other populations indicating the need to be aware of such differences when undertaking surgical procedures around the MF.

KEY WORDS: Mental Foramen; Accessory Mental Foramen; Double Mental Foramen; Mandible; Khyber Pakhtunkhwa.

\section{INTRODUCTION}

Anesthetizing patients for dental procedures in the mandibular region is challenging (Agarwal \& Gupta, 2011) due to anatomical variations in the location, size, shape and vertical orientation of mental foramen (MF), through which the inferior alveolar nerve and vessels pass (Al-Khateeb et al., 2007), as well as a potential lack of anatomical knowledge of the mandibular region in dentists.

The inferior alveolar nerve provides a sensory supply to the lower lip, labial mucosa, lower canines and premolars. Its terminal branch, the mental nerve (MN), exits the MF and then gives 4 branches (angular, medial, lateral, inferior labial) (Budhiraja et al., 2012). Identification of the $\mathrm{MN}$ is problematic during open reduction of mandibular fractures
(Concepcion \& Rankow, 2000). To anesthetize the mandibular teeth, the most useful procedure is an inferior alveolar nerve block (Gupta \& Soni, 2012).

The MF is present bilaterally on the anterolateral aspect of the mandible (Hasan, 2011): it and may be round or oval (Ilayperuma et al., 2009). It is normally located between the premolars, with additional foramina (accessory mental foramen, AMF) located below the first molar (Cagirankaya \& Kansu, 2008 cited by Thakur et al., 2011).

The presence of AMF is rare, however they may be single or double. Therefore, particular attention should be given to AMFs when undertaking surgical procedures in the

* Center for Anatomy and Human Identification University of Dundee Scotland, United Kingdom.

** North West School of Medicine sector A 3 Phase 5 Hayatabad Peshawar, Pakistan.

*** Department of Biochemistry Khyber Medical University Peshawar, Pakistan.

***** Bridge Consultants Foundation Karach, Pakistan.

****** Department of Anatomy Peshawar Medical College Peshawar, Pakistan. 
mandibular region to avoid neurovascular complications (Imada et al., 2014). The accessory mental nerve (AMN), a branch of the inferior alveolar nerve, mainly exits from the AMF: AMN injury usually results in paresthesia of the area supplied (Jha \& Kumar, 2012). The AMN is of particular importance during surgical procedures as its presence may be missed and may lead to persistent neurologic pain (Khojastepour et al., 2015).

Positional variations of the MF have been observed, being between the apices of lower premolars as well as below the apex of second premolar. Similarly, knowledge of the existence of an AMF would also reduce the potential of AMN injury during periapical surgery (Naitoh et al., 2009).

MF variations have been reported in different ethnic groups: failure to identify it during surgical procedures indicate the presence of variations within a given population (Neves et al., 2010). MF anatomy is also important in the evaluation of morphometric symmetry of the mental triangle, microscopic and macroscopic morphology and maturity of the human mandible, bone remodeling activity and paleoanthropologic features of the facial skeleton in different populations (Ngeow \& Yuzawati, 2003).

Although some studies have been conducted describing the surgical anatomy of the mandible, to the best of our knowledge no such research has been conducted in Pakistan. With a lack of adequate roads and the associated road traffic accidents, the number of mandibular injuries in Pakistan is relatively high. Since a large proportion of such injuries require surgical intervention, knowledge of the anatomy of the anterior mandible, including the $\mathrm{MN}$, in this population is important. The main objective, therefore of the current study was to assess anatomical variations of the $\mathrm{MN}$ in a population from Khyber Pakhtunkhwa (KP) province Pakistan, which would aid surgeons in locating the MF and AMF and thus avoid trauma to the associated neurovascular structures.

\section{MATERIAL AND METHOD}

Participants. One hundred and nineteen human mandibles of unknown age and sex from different KP medical institutions were examined. Assessments of mandibles of the same race (i.e. brown Caucasian) were undertaken in Anatomy departments of medical schools. The location, shape, size and position of the MF and AMF (if present) were determined for each mandible. For this study ethical approval was obtained from the local review board committee.
Measurements. The dimensions and position of MF and AMF were recorded using a digital caliper (eSecure ${ }^{\circledR} \mathrm{UK}$ ). The distances measured were: MF length and width; AMF width; MF to midline (MF-ML) (Fig. 1), MF to the upper (MF-UM), lower (MF-LM) and posterior border of the mandibular ramus (MF-PRM), and similarly for the AMF (AMF-ML, AMF-UM, AMF-LM and AMF-PRM). AMF position in relation to the MF was also noted.

When present additional foramina were assessed to determine whether they were accessory MFs or constituted a double MF. Passing a fine bristle into the foramen, if it passed into the mandibular canal it was considered to be an accessory mental foramen (AMF), otherwise it was considered to be a double mental foramen (DMF) (Fig. 2).

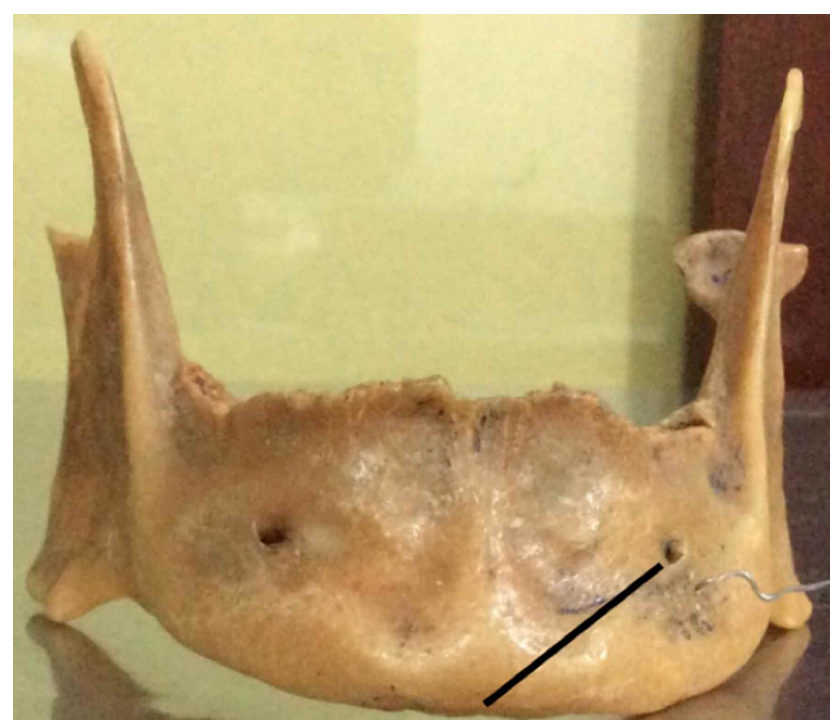

Fig. 1. The distance between the mental foramen (MF) and the mandibular midline (symphysis menti) on the left side.

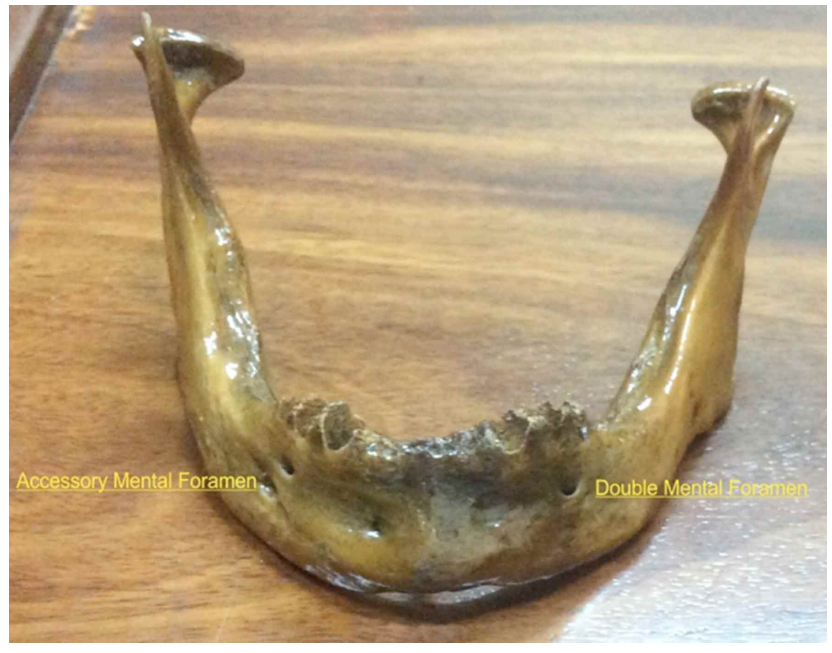

Fig. 2. Mandible with an accessory mental foramen (AMF) on the right and a double mental foramen (DMF) on the left. 
Analysis of data. Validity checks were undertaken to evaluate data entry into an Excel spreadsheet, following which the data was exported to Minitab ${ }^{\circledast}$ version 17 (Minitab corporation Illinois, USA) for subsequent analysis. Right and left side distances were compared using paired sample t-tests.

\section{RESULTS}

The MF were mainly oval (43.7\% right, $46.0 \%$ left) and situated below the second premolar tooth $(48.7 \%$ right, $51.26 \%$ left). DMFs were observed on both sides (10.9\% right, $12.6 \%$ left) and were mainly oval: on the left they were situated below the $1^{\text {st }}$ premolar. The mean values, and their associated standard deviations, for the various distances measured are presented in Table I: no significant difference was observed between the right and left sides for any distance measured. DMF width and length were significantly less than the width and length of main MFs.

An oval AMF (Fig. 2) was observed in one mandible on the right side below the $1^{\text {st }}$ premolar (width, $2.56 \mathrm{~mm}$; length, $1.43 \mathrm{~mm}$ ) and was $4.8 \mathrm{~mm}$ from the MF. The following distances were observed: AMF-ML, $29.16 \mathrm{~mm}$; AMF-UM, $10.02 \mathrm{~mm}$, AMF-LM, $9.34 \mathrm{~mm}$, and AMF-PRM, $61.65 \mathrm{~mm}$.

Table I. Length and width of single and double mental foramen (MF), together with the distance of the MF from the midline (ML), upper margin (UM), lower margin (LM) and posterior border of the mandibular ramus (PRM). * value significantly smaller $(\mathrm{P}<0.01)$ than corresponding single MF value.a

\begin{tabular}{lcc}
\hline & Right side & Left Side \\
\hline Single MF: length (mm) & $2.4 \pm 0.89$ & $2.4 \pm 0.73$ \\
Single MF: width (mm) & $3.0 \pm 0.80$ & $2.9 \pm 0.94$ \\
MF-ML distance (mm) & $29.1 \pm 2.19$ & $28.1 \pm 2.12$ \\
MF-UM distance (mm) & $11.0 \pm 3.99$ & $11.2 \pm 3.98$ \\
MF-LM distance (mm) & $13.1 \pm 1.83$ & $12.8 \pm 1.74$ \\
MF-PRM distance (mm) & $69.3 \pm 5.52$ & $68.7 \pm 5 / 02$ \\
Double MF: length (mm) & $0.7 \pm 0.42^{*}$ & $0.8 \pm 0.32^{*}$ \\
Double MF: width (mm) & $0.9 \pm 0.34^{*}$ & $1.0 \pm 0.47^{*}$ \\
DMF-MF distance (mm) & $8.9 \pm 4.58$ & $6.6 \pm 4.11$ \\
\hline
\end{tabular}

\section{DISCUSSION}

MF in the current study were mainly oval (43.7\% right, $46.0 \%$ left), being similar to the observations of Ilayperuma et al. on Sri Lankan human mandibles (Australoid race). They were mainly located below the second premolar (48.7\% right, $51.26 \%$ left), a finding similar to Ngeow et al. in a Malaysian (Malay) population. Mean MF length in the present study was less than that reported in a South Gujarat population by Agarwal \& Gupta (3.33 mm right, $3.25 \mathrm{~mm}$ left: range 2.1-6.2 $\mathrm{mm}$ ), while the mean width was greater $(2.15 \mathrm{~mm}$ right, $2.13 \mathrm{~mm}$ left: range $1.8-3.1 \mathrm{~mm}$ ). The distance of the MF from the midline was considerably greater than that observed by Ilyperuma et al., in Sri Lankan mandibles, which they reported as $24.87 \pm$ 6.07 (right) and $24.77 \pm 6.07 \mathrm{~mm}$ (left). The distance from the MF center to the UM was similar, while the MF-LM distance was less than that reported by Rastogi et al. (2012) in central India human mandibles (MF-UM: $10.67 \pm 0.21 \mathrm{~mm}$ right, $10.71 \pm 0.18 \mathrm{~mm}$ left: MF-LM $14.59 \pm 0.23 \mathrm{~mm}$ right, $14.64 \pm 0.20 \mathrm{~mm}$, left). Furthermore, the MF-PRM distance was greater than the $65.38 \mathrm{~mm}$ reported by Prabodha \& Nanayakkara (2006) in Sri Lankan mandibles.

Unlike Budhiraja et al., who reported a unilateral AMF in 7 North Indian mandibles and Khojastepour et al. who observed AMF in 8 Iranian mandibles, a single AMF was observed in 1 mandible in the current study. The distance between the AMF and MF was $4.8 \mathrm{~mm}$, smaller than the 6.3 $\mathrm{mm}$ reported by Naitoh et al. While the AMF was below the 1 st premolar in the current study this differs from Imada $e t$ $a l$. who reported it mainly between the premolars in their study of Brazilian mandibles. A greater incidence of double mental foramen (DMF) were observed than the Greek population studied by Zografos et al. (1989) (6.68 \%: 6.41 $\%$ in males, $6.95 \%$ in females).

It is clear from the above comparisons that there are differences not only in the position of the MF in relation to the mandibular midline, upper and lower mandibular margins and posterior border of the mandibular ramus, but also in the occurrence of accessory and double MFs. While such differences may be relatively small they may nevertheless be significant in surgery involving the anterior mandible.

In conclusion no difference was observed between right and left side MFs in the population studied. When present DMFs were significantly smaller than single MFs. A single AMF was observed, while double MFs were present on both sides in 10-12\% of mandibles. The data presented here highlights racial differences in the dimensions and location of the MF, as well as in the occurrence of AMFs and DMFs that should to be taken into consideration when undertaking surgical procedures involving the anterior mandible in order to avoid trauma to the associated neurovascular bundles.

ACKNOWLEDGEMENTS. Dr. Zulkarnain (Research Associate, The University of Agriculture, Peshawar, Pakistan). 
BADSHAH, M.; SOAMES, R.; KHAN, M. J.; HASNAIN, J. \& KHAN, J. Morfometría del foramen mental en una población de Khyber Pakhtunkhwa (KP), Pakistan. Int. J. Morphol., 34(3):1228-1231, 2016.

RESUMEN: El conocimiento de las variaciones del foramen mental (FM), su ubicación, tamaño y forma es importante al momento de anestesiar los nervios de la región mandibular en procedimientos dentales. La ubicación, forma y posición del FM se determinó en 119 mandíbulas humanas, de edad y sexo desconocidos, de diferentes instituciones médicas de Pakistan. Los parámetros determinados fueron: longitud y ancho; ancho del foramen mental accesorio (FMA); MF y AMF a la línea mediana (FM-LM) (FMA-LM), margen superior (FM-MS) (FMA-MU) y margen inferior (FM-MI) (FMA-MI) y el margen posterior de la rama mandibular (FM-RMP) (FMA-RMP). También se observó la posición del FMA en relación con el FM. La forma del FM fue principalmente ovalada y situado por debajo del segundo premolar. Los datos de longitud y anchura del FM fueron: 2,4 $\pm 0,89$ (derecha) y $2,4 \pm 0,727 \mathrm{~mm}$ (izquierda), y $3,0 \pm 0,80$ (derecha) y $2,9 \pm 0,94 \mathrm{~mm}$ (izquierda), respectivamente. Las distancias FM-LM, FM-MS, FM-MI y FM-MRP en el lado derecho e izquierdo fueron: $29,1 \pm 2,19 \mathrm{~mm}$ y $28,1 \pm 2,12 \mathrm{~mm} ; 11.0 \pm 3.99 \mathrm{~mm}$ y $11,2 \pm 3,98 \mathrm{~mm} ; 13,1 \pm 1,83 \mathrm{~mm}$ y $12,8 \pm 1,74 \mathrm{~mm} ; \mathrm{y} 69,3 \pm$ $5,52 \mathrm{~mm}$ y $68,7 \pm 5,02 \mathrm{~mm}$, respectivamente. Se observaron foramenes mentales dobles (FMD) en ambos lados (10,9\% derecho, 12,6\% a la izquierda) con una longitud y ancho de $0,7 \pm 0,42 \mathrm{~mm}$ y $0,9 \pm 0,34 \mathrm{~mm}$ (derecha) y $0,8 \pm 0,32 \mathrm{~mm}$ y $1,0 \pm 0,47 \mathrm{~mm}$ (izquierda): fueron principalmente ovalados (5,8 $\%$ derecha, izquierda 7,56 \%). La distancia FMD-FM fue de $8,9 \pm 4,58 \mathrm{~mm}$ a la derecha y 6,6 $\pm 4,11 \mathrm{~mm}$ en el izquierdo. Se observó un foramen mental accesorio ovalado en una mandíbula. Hubo diferencia entre FM derecho e izquierdo. Sin embargo, las diferencias en los parámetros medidos fueron observados en relación con otras poblaciones que indican la necesidad de ser conscientes de estas diferencias al realizar procedimientos quirúrgicos en todo el MF.

\section{PALABRAS CLAVE: Foramen mental; Foramen mental accesorio; Foramen mental doble; Mandíbula; Khyber Pakhtunkhwa.}

\section{REFERENCES}

Agarwal, D. R. \& Gupta, S. B. Morphometric analysis of mental foramen in human mandibles of South Gujarat. People's J. Sci. Res., $4(1): 15-8,2011$

Al-Khateeb, T.; Al-Hadi Hamasha, A. \& Ababneh, K. T. Position of the mental foramen in a northern regional Jordanian population. Surg. Radiol. Anat., 29(3):231-7, 2007.

Budhiraja, V.; Rastogi, R.; Lalwani, R.; Goel, P. \& Bose, S. C. Study of position, shape, and size of mental foramen utilizing various parameters in dry adult human mandibles from north India. I. S. $R$. N. Anat., 2012:961429, 2012.

Concepcion, M. \& Rankow, H. J. Accessory branch of the mental nerve. J. Endod., 26(10):619-20, 2000.

Gupta, S. \& Soni, J. S. Study of anatomical variations and incidence of mental foramen and accessory mental foramen in dry human mandibles. Nat. J. Med. Res., 2(1):28-30, 2012.

Hasan, T. Characteristics of the mental foramen in different populations. Internet J. Biol. Anthropol., 4(2):14, 2011.

Ilayperuma, I.; Nanayakkara, G. \& Palahepitiya, N. Morphometric analysis of the mental foramen in adult Sri Lankan mandibles. Int. J. Morphol., 27(4):1019-24, 2009.

Imada, T. S.; Fernandes, L. M.; Centurion, B. S.; de Oliveira-Santos, C.; Honório, H. M. \& Rubira-Bullen, I. R. Accessory mental foramina: prevalence, position and diameter assessed by cone-beam computed tomography and digital panoramic radiographs. Clin. Oral Implants Res., 25(2):e94-9, 2014.

Jha, A. K. \& Kumar, N. G. Accessory mental nerve: case report, review and its role in trigeminal neuralgia. Surg. Radiol. Anat., 34(5):469$73,2012$.

Khojastepour, L.; Mirbeigi, S.; Mirhadi, S. \& Safaee, A. Location of mental foramen in a selected Iranian population: A CBCT assessment. Iran. Endod. J., 10(2):117-21, 2015.
Naitoh, M.; Hiraiwa, Y.; Aimiya, H.; Gotoh, K. \& Ariji, E. Accessory mental foramen assessment using cone-beam computed tomography. Oral Surg. Oral Med. Oral Pathol. Oral Radiol. Endod., 107(2):289-94, 2009.

Neves, F. S.; Oliveira, L. S. A. F.; Torres, M. G. G.; Crusoé-Souza, M.; Oliveira, C.; Campos, P. S. F. \& Crusoé-Rebello, I. Accessory mental foramen: case report. R. P. G. Rev. Pós-Grad., 17(3):173-6, 2010.

Ngeow, W. C. \& Yuzawati, Y. The location of the mental foramen in a selected Malay population. J. Oral Sci., 45(3):171-5, 2003.

Prabodha, L. B. L. \& Nanayakkara, B. G. The position, dimensions and morphological variations of mental foramen in mandibles. Galle Med. J., 11(1):13-5, 2006.

Rastogi, R.; Budhiraja, V.; Sathpathi, D. K.; Singh, S.; Gour, K. K. \& Nair, S. Morphology and morphometry of the mental foramen in dry adult human mandibles from central India and their clinical correlation. Eur. J. Anat., 16(1):22-6, 2012

Thakur, G.; Thomas, S.; Thayil, S. C. \& Nair, P. P. Accessory mental foramen: a rare anatomical finding. B. M. J. Case Rep., 2011.pii:bcr0920103326, 2011

Zografos, J. \& Mutzuri, A. Incidence of double mental foramen in a sample of Greek population. Odontostomatol. Proodos., 43(6):521-3, 1989.

Correspondence to:

Dr. Masroor Badshah

Center for Anatomy and Human Identification

University of Dundee Scotland UK

North West School of Medicine

Sector A 3 Phase 5 Hayatabad Peshawar

PAKISTAN

E-mail: masroorbadshah@outlook.com

Received: 25-04-2016

Accepted: 10-08-2016 